\title{
Principles of Implant Implementations for Restorations of Extra-Oral Defects
}

\author{
Chawla P*, Raheja R, Chaudhary R, Pal S \\ MDS, Department of Prosthodontics and crown and bridge and implantology, Rama dental college, hospital and research centre, \\ 124/399, Block 11A , Govind nagar, Kanpur, Uttar Pradesh 208024
}

\section{*Corresponding Author \\ Chawla P}

\section{Article History}

Received: 22.06.2019

Accepted: 12.07 .2019

Published: 30.07 .2019

\begin{abstract}
Many large tissue defects occur with surgery treatments of tumors in the maxillofacial region. Maxillofacial prosthesis application can be used as an alternative treatment for cases where plastic surgery reconstructions cannot be applied. While the retention of maxillofacial prostheses used to be provided generally via adhesive bands, adhesives in liquid or spray form, and tissue undercuts, the current treatment of an intra-oral edentulous condition is frequently conducted via osseo-integrated implants.
\end{abstract}

Keywords: Auricular prosthesis, Combined defect prosthesis, Extra oral implants, Nasal prosthesis, Ocular prosthesis

\section{INTRODUCTION}

Implants Used in Maxillofacial Prosthetic Treatments

- Intra-oral Implants

- Extra-oral Implants

\section{EXTRA-ORAL IMPLANTS}

\section{General Principles of Implant Supported Restorations of Extraoral Defects}

- Implant abutments must be as optimal as the covering skin can provide,

- For preventing destructive forces, subcutaneous skin layers should be thinned surgically, and this process must be performed $10 \mathrm{~mm}$ away from abutments,

- Implants should be $1 \mathrm{~cm}$ away from each other for hygienic purposes,

- Bars fixed between abutments must be in accordance with natural contours of the face and they must be designed in order to provide required hygiene needs,

- Implants must be placed at least $7 \mathrm{~mm}$ away from hairy skin. If that is not possible, a skin graft must be applied.

\section{Auricular Prostheses}

Auricular defects constitute $70 \%$ of all maxillofacial defects. Surgical reconstruction of the auricular helix requires a surgery series taking a couple of years. An obtained auricular helix may not appear original and may not create a symmetrical face appearance. Transcutaneous implant usage is seen as an effective treatment option for auricular prostheses. By using this technique, it is possible to fabricate prostheses which are similar to anatomical structures and do not create trauma in the nearby tissues. These prostheses include retentive mechanisms. The position of implants on the temporal region is very important for the aesthetic of auricular prostheses. Implants should be placed at the anti-helix level because retention systems need to be placed inside of the borders of auricular prostheses. Two pieces of implants placed in the temporal region can provide the retention of auricular prostheses. In such cases, two implants must be placed within $15 \mathrm{~mm}$ away from each other and each of them must be $18 \mathrm{~mm}$ away from the center of the auricular canal. One implant must be placed in the 9 o'clock position and the other in the 11 o'clock position for the right auricular, and one in the 1 o'clock position and the other in the 3 o'clock position for the left auricular (Figure 1). These traditional proposals should be accepted as a fixed principle. The exact positions of implants must be determined by producing a wax sample and using a surgical stent. First of all, a wax model should be shaped for auricular prostheses in accordance with anatomical auricular specifications and then it will be placed such that it provides face symmetry. By using a wax auricular, a surgical stent can be

Copyright @ 2019: This is an open-access article distributed under the terms of the Creative Commons Attribution license which permits unrestricted use, distribution, and reproduction in any medium for non commercial use (NonCommercial, or CC-BY-NC) provided the original author and source are credited. 
produced from acrylic resin or vinyl acetate. When it is placed, the surgical stent must indicate the most appropriate regions to place the implants. For auricular prostheses, generally two different retention systems are preferred and may be used alone or in combination. For the first system, a gold base alloy bar is used in $2 \mathrm{~mm}$ diameter form. This bar is soldered on a gold cylinder and then attached to implant abutments. The retention clips attaching the prosthesis to the bar are included in the prosthesis.

The usage of the bar and clips system provides efficient prosthesis retention and force distribution. However, because the prosthesis includes a base part covering the bar, it is very difficult to reach the region beneath the bar and to clean it. Because retention is provided too effectively, insertion and extraction of the prosthesis may be difficult for patients who cannot use their hands effectively. In such cases, magnet auricular prostheses would be a better choice. The second retention method is the magnet technique. The first method of this technique is to use a bar and magnets together. A bar structure attached to implant abutments is designed to create a seat for magnets. Magnets are placed into those seats by using acrylic resin. The other pair of magnets is placed into the silicone prosthesis. The magnets used in that system generally have a $6 \mathrm{~mm}$ diameter and $2 \mathrm{~mm}$ thickness. The bar-magnet system may create hygiene and aesthetic problems because they increase the volume of the structure which provides the retention [1-5].

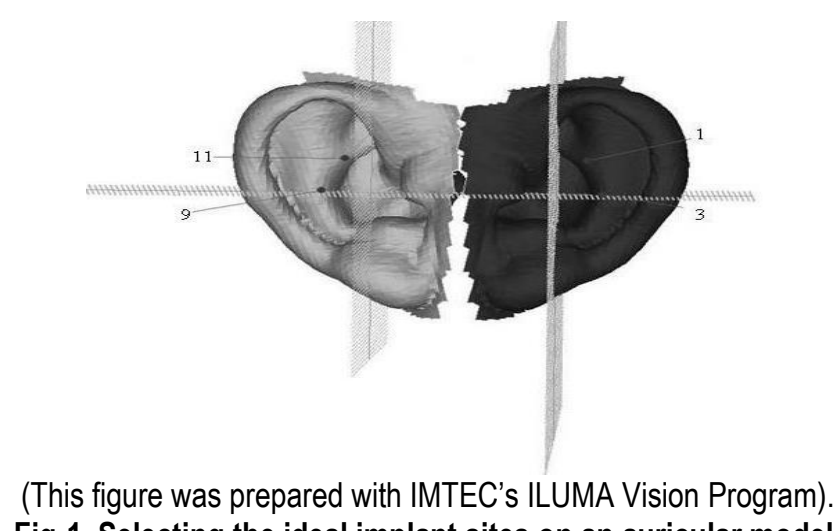

Fig-1. Selecting the ideal implant sites on an auricular model.

The third alternative is to use a magnet system without using bars [6]. In this technique, magnets are directly attached to implant abutments. The main advantage of this technique is that it easily hides implant abutments inside of the borders of the prosthesis. The previous periods of implant placement in auricular prosthesis has included the usage of four implants as reinforcement. Currently, it is accepted that two implants are enough to provide retention and reinforcement or auricular prostheses.

\section{Nasal Prostheses}

Nasal defects constitute $6 \%$ of all maxillofacial defect cases. The anterior nasal spine region beneath the nasal cavity has enough thickness to accommodate $3-6 \mathrm{~mm}$ implants (Figure 2). The wax nasal model shaped before surgery may help in the determination of locations where implants will be placed and planning such that the holders will not affect the prosthetic contours [7,8], [5]. In order to provide a stable surface for nasal prostheses, the defect region should be covered with a semi-thick skin graft. This process eliminates the destructive effects by decreasing the mobility of auxiliary tissues beneath the prosthesis. In order to increase stability, nasal prostheses should be extended through the lateral wall of the defect. For this purpose, anterior septal cartilage should be surgically lifted. To place one implant on each of two nasal eminence regions would provide enough retention. It is also recommended that abutments should be attached to each other with a bar and that bar must pass $15-20 \mathrm{~mm}$ over the abutments.

\section{Orbital Prostheses}

Orbital defects constitute $20 \%$ of all cases. The problems which adhesives create in the temporal region are seen more frequently in the orbital region. Due to the adhesive coverage of orbital defect edges, consisted moisture causes inflammation in the soft tissues and it may therefore decrease the quality of life of the patient [9-12]. Implant usage for the retention of orbital defects increases adhesive needs and prostheses became easier to use. They can be inserted and extracted without serious effort. This easyto-use specification causes effective ventilation and protection of tissue health. For the retention of an orbital prosthesis, bar and magnet systems are used. Generally, the bone, which has enough volume to place the implant in the orbita, exists in the lateral edge of the orbita. However, 3-4mm implants can be placed on bones at inferior, superior, and lateral regions of the orbita. Generally, three or four implants are required (Figure 3). The long axe of implants should traverse through the center of the orbita. The bar with a monoblock entrance way may not be achieved if some implants are heading in a posterior direction (cranial fossa) and some are heading in the reverse direction. If implants exist in both the upper and lower edges, generally, independent magnet systems are preferred. The wax sample of final prostheses must be used as a surgical stent in order to provide retention and an aesthetic improvement $[13,14]$. The curved structure of the lateral wall of the orbita, the limited existence of bone, and limited accessibility of the region make restoration and implant protection more difficult. The circular positions of implants may make the production of a retention bar passively holding to all implant abutments more difficult. The bar also makes access to soft tissue around the implant abutments difficult. When magnet holders are used together with a bar, the accessibility problem of tissues is increased even more. 
The usage of magnets without a bar makes prosthetic processes easier and increases hygiene. Magnets help prostheses to find true positions during placement. Two or three implants are enough for retention of auricular prostheses.

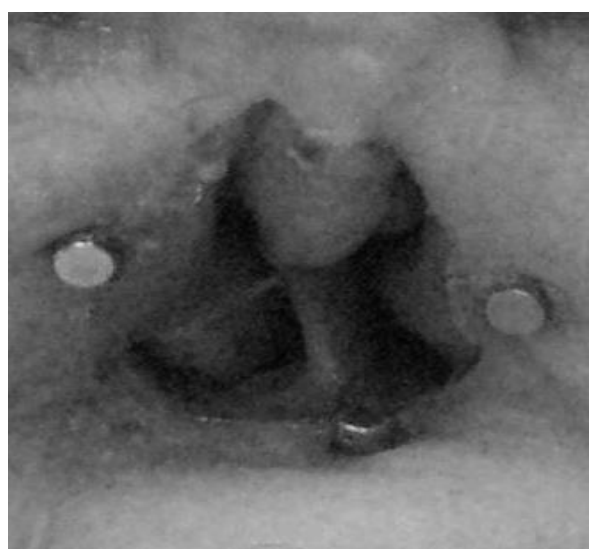

Fig-2. Using implants in nasal defects.

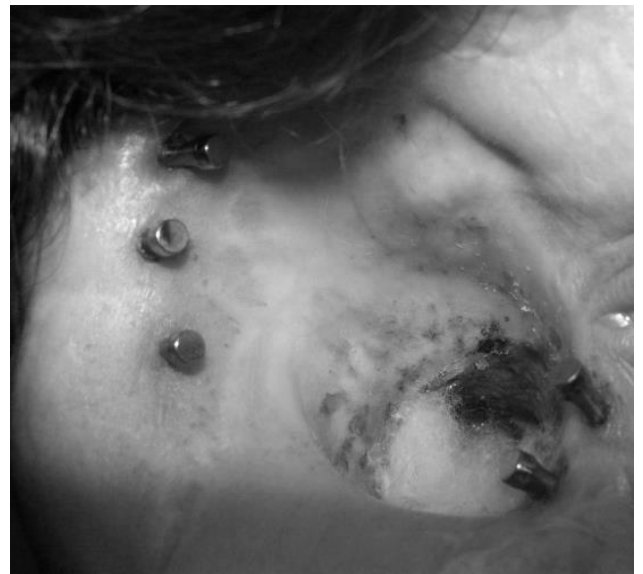

Fig-3. Using implants in orbital defects.

\section{Ocular Implants}

Ocular implants are materials placed into tissue sockets in order to make the production of prostheses easier. In 1960, Allen et al. [15] developed and embedded acrylic implant into canals for the passage of muscles for ocular prostheses. Then, by burrowing holes in acrylic Allen type implants rather than canals for the passage of muscles, the lowa and Universal implants entered into usage. Today, most of the ocular prostheses are made of thermoresistant, strong, light, and unbreakable acrylic materials. If any material is not used in order to fill the empty space, there is a collapsed appearance because the size of the eye is restrained by a gap between the upper and lower eye lids. When the muscles move normally, the implant connected to ocular muscles also moves. So, the prosthesis gains movement ability and more realistic prostheses are obtained. For a growing child, the muscle function obtained by implementing an implant creates retention on orbital walls, providing the normal development of orbital growth.

\section{Implant's Placement}

Muscles are dissected from sclera after enucleation, where an implant is placed to control hemorrhaging, and ocular muscles are connected to the implant. Superior and inferior rectus muscles are sutured at 12 and 6 o'clock positions. After suturing the first two muscles, lateral and medial rectus muscles are sutured on the anterior surface of the implant at 3 and 9 o'clock positions. In order to prevent the implant from sinking into the eye socket base, inferior oblique muscles are sutured to superior rectus muscles. The suturing of the lateral rectus also decreases the ptosis. The plastic conformer is placed on the sutures and under the eye lid [1618].

\section{Implant Types}

There are three basic ocular implant types:

An embedded implant is shaped like a sphere. The implant provides the movement for the prosthesis by moving the tissue bed where the prosthesis is placed.

A semi-embedded integrated implant is placed in a cone which is established by the ocular muscles. The frontal surface of the implant consists of a net system which is placed near the gap. Rectus muscles are connected to those nets. The eye prosthesis is made of male parts according to a gap in the implant. This improves the movement of the implant eye prosthesis, but generally is susceptible to infection and becomes lost is $2-5$ years.

An embedded semi-integrated implant includes a body to which muscles are sutured or connected. When producing personal prostheses, an adverse contour is made on the back surface of the ocular prosthesis. There is always a tissue separating the artificial eye from the implant. So the movement opportunity can be protected, even if it is very limited. In fact, porous implants are made of an inorganic calcium phosphate salt, which is the main element of the human bone's inorganic matrix. Recently, bio-ceramic orbital implants have been developed in France (aluminum oxide, Alümina). It was approved by the FDA in America in 2002. Research regarding ideal prostheses is still ongoing. The artificial eye was developed in order to provide a solution for people who lost their eyes in an accident or from a disease. But recently, researchers developed a robotic eye prosthesis which can perform all the duties of a real eye except seeing. The robotic eye is run by a small motor which shifts the eye ball according to the signals coming from the brain via electrodes at two sides of head. Orbital implants are classified in different ways in terms of applied surgical technique, material type, shape, etc. According to standard surgical technique, they are classified into two main groups as integrated and non-integrated orbital implants. The non-integrated implants are placed inside the orbital, behind the tendon, and in the muscle cone. But there is no direct connection between muscles and the implant and they are generally spherically shaped. Integrated implants are directly 
connected with muscles. Also, those implants are classified into two groups as covered and non-covered implants. The covered implants are covered by a tendon and conjunctiva after the muscles are sutured. They may be shaped spherically or without any order. Some part of the implant is covered by different tissues, such as sclera, fascia lata, and dura mater, and then muscles are sutured to that tissue. Some implants have tunnels and sockets through which the muscles can be passed and then sutured. According to the material's structure, orbital implants are classified into two classes as solid (glass, acrylic, silicon, etc.) and porous. According to development order, porous implants are cattle spongiform bone, sea bream based hydroxyapatite, porous polyethylene, synthetic hydroxyapatite, and bio-ceramic [19-26]. The hydroxyapatite (HA) ocular implant was first used by Perry [27]. In order to increase movement, Perry planned the usage of this material in 1983, while basic research studies were performed from 1983 until 1985. After enucleation and evisceration, HA implants were implemented to more than 80 patients from 1985 until 1989 in the scope of experimental protocol which is provided by the FDA. In 1989, the FDA approved the usage of HA as an orbital implant and released the usage.

\section{Porous Orbital Implants}

Porous implants are the most studied implants in recent years, and they are embedded and may be integrated to prostheses. They are, in fact, made from an inorganic calcium phosphate salt, which is the main element of human bone's inorganic matrix. HA has been used in reconstruction of orthopedic, maxillofacial, and maxillodental regions instead of bone. When it is used instead of bone, vascular elements and lamellae coalesce with bones and take place in reinforcement tissue. The aragonite (CaCo3, calcium carbonate) obtained from porites class bream can be transformed into calcium phosphate hydroxyapatite (Ca ( $\mathrm{PO} 4) 6(\mathrm{OH} 2))$ via a special hydrothermal reaction. The obtained material consists of ordered and mutually connected canals with a 500 micron diameter. They have many similarities with a bone's normal Havers system [24]. After the placement of that porous material into the orbita after enucleation and evisceration, it begins to be filled with fibro-vascular tissue. In approximately 4-6 months, the implant becomes filled almost completely in most of patients and it becomes a part of body. It is thought to minimize the infection development and risk of opening. Due to those specifications, the porous orbital implants showed advanced developments against the integrated implants which were used before.

\section{Orbital Implant Size}

The volume loss due to enucleation and evisceration is generally solved by allocating between prostheses and spheres which are implanted in the muscle conus. Enucleation leads to a $25-30 \%$ loss in total volume of the orbita (6.5-7ml). The functions of orbital implants are to prevent retention of orbital tissues, to compensate for the volume loss caused by removing the eye, to reinforce the stability of prostheses, and to improve the mobility of prostheses. The volume of an eye ball is $7.2 \mathrm{ml}$, but the volume of a prosthesis is approximately $2.5 \mathrm{ml}$.

For this reason, the volume of an orbital implant must be identical to the difference between the volume of the prosthesis $(2.5 \mathrm{ml})$ and the volume of the removed eye $(7.2 \mathrm{ml})$. If any implant with a smaller diameter than $21 \mathrm{~mm}$ is used, the possibility of volume decrease in the orbita space is very high. In the beginning, the highest diameter which could be used was thought to be $18 \mathrm{~mm}$. People believed that if they used an implant larger than $18 \mathrm{~mm}$, the conjunctiva and tendon could be closed only by pressure, and so the implant could possibly be lost. For most adult patients, an implant with a $20-22 \mathrm{~mm}$ diameter can be easily and without pressure placed into the tendon capsule and muscle conus. If any fatty atrophy, orbital soft tissue fibrosis, or retraction exists in the orbita or if any surgical operation is performed before enucleation, a larger implant is required [19],[27,29],[16],[30-32],[21],[13,14],[22],[25].

\section{There are several specifications which an ideal orbital implant must have:}

- The implant must be embedded totally,

- It should be implemented easily,

- It should be light-weight,

- It should be smaller than a real glob and it should have enough volume for the prosthesis,

- It should be able to be placed in muscle conus,

- It should be inert and should not lead to any reaction,

- Its structure should not allow any migration and exposition development,

- It should not be resorbed over time,

- Extra-ocular muscles must attach to the implant easily,

- The prosthesis integration must be done completely for a complete transfer of movement.

The deep implant implementation into the muscle conus has some advantages:

- Larger implants may be used, and the enophthalmos and volume loss can be prevented,

- The risk of migration and exposition can be decreased,

- $\quad$ The tendon can be used for covering the implant as much as the anterior tendon capsule. So, the layer between the implant and conjunctiva can be reinforced. Porous implants are thought to fulfil most of those duties. The most important specifications of those implants are to be able to be vascularized and to be able to lead to appropriate results for integrating the prosthesis and implant; 
- Because of vascularization, the infection risk is very low33,

- The passage of fibro-vascular tissue through implant pores decreases the migration and exposition risk,

Most of the weight of the prosthesis is carried by the implant via a pin. So, the weight is taken from the bottom eye lid, and the risk to the bottom eye lid and fornix ptosis decreases. The pulverization starts a few weeks after porous orbital implants are implemented into thetendon space after enucleation or into the sclera pouch after evisceration, but the complete vascularization requires at least 4-6 months $[28,18,34]$. After the end of this period, the completely mobile prosthesis can be achieved via pin implantation. In order to visualize the vascularization, many different methods are used, including bone scintigraphy, Magnetic Resonance (MR), Ultrasound, and Colored Doppler. In Tec99m bone scintigraphy, Methylene Di-phosphate (MDP) is used as radionuclide material. Through an unknown mechanism, Tec99m showed that MDP accumulates at immature collagen of bone minerals. After implementing MDP intravenously, the visualization is performed in each of two lateral positions in 2-2.5 hours. MDP is stored in implant in proportion to vascularization. The MR contrasted with Gadolinium- DTPA is used in the other method. A 20ml contrast material is applied intravenously for more than 2 minutes; MR is started in 5 minutes. Some advantages of MR over against bone scintigraphy include the following:

- $\quad$ MR is a more sensitive and reliable method,

- MR provides 3D imaging and, thereby, more detailed information is available,

- The patient is not exposed to radioactive material by using MR, so its application is healthier,

- We can get information about qualification of vascularization via MR.

Because the sectioning is available via MR, the whole sphere can be evaluated. Normally, vascularization starts at the periphery and continues through the center. With MR, this separation can be made, and both vascularized and non-vascularized parts can be determined.But because the counting is made from abroad, the vascularization in the periphery may mask the space in the center and false results may be obtained.

Besides all those advantages, the biggest disadvantage of MR is that its price is higher than that of other methods. The vascularization of porous orbital implants is required for covering the base and fornix with a hole which is obtained by screwing the conjunctival epithelium. This epithelium protects the implant from outer effects, particularly form infection. The epithelization of the hole which is opened after the screwing process and after successful blood builds up is finished in 4- 6 weeks. When the porous orbital implant is placed into the orbita, it leads to a minimally inflammatory reaction which is both non-allergenic and non-toxic. Reactions with giant cells are seen infrequently; it is reported in this reaction that the giant cells on the outer surface of the implant which keeps company with soft tissues shows osteoclastic activity $[35,36]$.

\section{CONCLUSION}

Combined defects constitute $2 \%$ of all defects. For a determination of appropriate implantation areas in the maxilla, nasal, and orbital regions, a guide wax prosthesis model should be created. By using panoramic radiography and computerized tomography, the thickness and density of bone structures should be determined. It is possible to place implants in the glabella region of the frontal bone, beneath zygomatic arc, on pterygoid bone, at upper and lower orbital edges, and in alveolar processes. Bone grafts must be placed where the bone reinforcement is not sufficient. Large limited combined defect placement on bony structures on the periphery is more appropriate for their resistance to loads from their long axes. Implants placed at the center of defects transfer destructive forces to bones to which they are attached by being exposed to Class I level forces during rotational movements of the prosthesis [37]. Trans-mucosal and trans-cutaneous implants can be used as combined implants in cases where intra- and extra-oral defects exist simultaneously.

\section{CONFLICT OF INTEREST- NO}

\section{REFERENCES}

1. Jacobsson, M., Tjellström, A., Fine, L. \& Jansson, K. (1992). An evaluation of auricular prostheses using osseointegrated implants. Clinical Otolaryngology \& Allied Sciences, 17, 482-486.

2. McKinstry, R. E. (1979). Fundamentals of Facial Prosthetics. Arlington; ABI Professional Publications: 1995. Muğan, N. Maxillofacial Prostheses. Istanbul: Gençlik Press.

3. O"Connell, J. E., Cotter. E. \& Kearns, G. J. (2011). Maxillary reconstruction using zygomatic implants: a report of two cases. J Ir Dent Assoc, 57, 146-55.

4. Parr, G. R., Goldman, B. M. \& Rahn, A. O. (1983). Surgical considerations in the prosthetic treatment of ocular and orbital defects. J Prosthet Dent, 49, 379-385.

5. Tolman, D. E. \& Taylor, P. F. (1996). Bone-anchored craniofacial prosthesis study. Int J Oral Maxillofac Impl, 11, $159-168$.

6. Atkins, A. D. \& Roper-Hall, M. J. (1983). Magnetic orbital implants. Br J Ophtalmol, 67, 315-316.

7. Jensen, O. T., Brownd, C. \& Blacker, J. (1992). Nasofacial Prostheses Supported by Osseointegrated Implants. Int J Oral Maxillofac Implants, 7, 203-211 
8. Nishimura, R. D., Roumanas, E., Moy, P. K., Sugai, T. \& Freymiller, E. G. (1998). Osseointegrated implants and orbital defects: UCLA Experience. J of Prosthet Dent, 79, 304-309.

9. Tolman, D. E. \& Taylor, P. F. (1996). Bone-anchored craniofacial prosthesis study. Int J Oral Maxillofac Impl, 11, $159-168$.

10. Nishimura, R. D., Roumanas, E., Sugai, T. \& Moy, P. K. (1995). Auricular prostheses and osseointegrated implants: UCLA experience. J of Prosthet Dent, 76, 553-558.

11. Parel, S. M., Branemark, P. I. \& Tjellstrom, A. (1986). Osseointegration in maxillofacial prosthetics Part II: extraoral applications. J Prosthet Dent, 55, 600-606.

12. Sarvananthan, N., Amanda, J. \& Liddicoat, G. T. (1999). Synthetic hydroxyapatite orbital implants: a clinical and MRI evaluation. Eye, 13, 205-8.

13. Yazıcıoğlu, H. \& Yafuğ, S.(1995). Custom ocular prosthetics. J of Gazi Univercity Faculty of Dentistry, 12, 117-120.

14. Kovacs, A. F. (2000). A follow-up study of orbital prostheses supported by dental implants. Int J Oral Maxillofac Implants, 58, 1923.

15. Nishimura, R. D., Roumanas, E., Sugai, T. \& Moy, P. K. (1995). Auricular prostheses and osseointegrated implants: UCLA experience. J of Prosthet Dent, 76, 553-558.

16. Hughes, M. O., Jou, E. M. \& Young, S. R. (2006). Lee Allen, Ocularist. J of Ophtalmic Prosthetics, 13-25

17. Dutton, J. J. (1990). Coroline hydroxyapatite as an ocular implant Ophthalmology, 3, 371- 98.

18. Hornblass, A., Biesman, B. S. \& Eviatar, J. A. (1995). Current techniques of enucleation: a survey of 5439 intraorbital implants and a review of the literature. Ophthalmol. Plast Reconstr Surg, 11, 77-86.

19. Perry, A. C. (1990). Integrated orbital implants. In: Bosniak SL, Smith BC, eds. Advances in Ophthalmic Plastic and Reconstructive Surgery. New York: Permagon Press;1990.

20. Arora, V., Weeks, M., Halperin, E. C. \& Dutton, J. J. (1992). Influence of corraline hydroxyapatite used as an ocular implant on the dose distribution of external beam photon radiation therapy. Ophthalmology, 99, 380.

21. Beumer, J., Curlis, J. A. \& Firteil, D. N. (1979). Maxillofacial Rehabilitation: Prosthodontic and Surgical Considerations. St.Louis: The C.V. Mosby Company.

22. Kazim, M., Katowitz, J. A., Fallon, M. \& Piest, K. L. (1992). Evaluation of a collagen hydroxyapatite implant for orbital reconstructive surgery. Ophthal PlastReconstr Surg, 82, 94-108.

23. Parel, S. M., Branemark, P. I. \& Tjellstrom, A. (1986). Osseointegration in maxillofacial prosthetics Part II: extraoral applications. $J$ Prosthet Dent, 55, 600-606.

24. Roumanas, E. D., Freymiller, E. G., Chang, T. L., Aghaloo, T. \& Beumer III, J. (2002). Implant-retained prostheses for facial defects: an up to 14-year follow-up report on the survival rates of implants at UCLA. Int J Prosthodont, 15, 325-322

25. Su, G. W. \& Yen, M. T. (2004). Current trends in managing the anophthalmic socket after primary enucleation and evisceration. OphthalPlast Reconstr Surg, 20, 274-80.

26. Wolfaardt, J. F., Wilkes, G. H. \& Anderson, J. D. (2000). Craniofacial Osseointegration-Prosthodontic Treatment. Illinois; Quintessence Publishing Co. Inc.

27. Yazıcıoğlu, H. \& Yafuğ, S.(1995). Custom ocular prosthetics. J of Gazi Univercity Faculty of Dentistry, 12, 117-120.

28. Roumanas, E. D., Freymiller, E. G., Chang, T. L., Aghaloo, T. \& Beumer III, J. (2002). Implant-retained prostheses for facial defects: an up to 14-year follow-up report on the survival rates of implants at UCLA. Int J Prosthodont, 15, 325-322.

29. Buettner, H. \& Bartley, G. B. (1992). Tissue breakdown and exposure associated with orbital hydroxyapatite implants. Am J Ophthalmol, 113, $669-73$.

30. Danz, W. Sr. (1990). Mobility implants: A review. Adv. Ophthalmic Plast Reconstr Surg, 8, 46-52

31. Jordan, D. R. (2004). Problems after eviseration surgery with porous orbital implants. Experience with 86 patients. Ophthal Plast Reconst Surg, 20, 374-380.

32. Jordan, D. R., Gilberg, S. \& Bawazeer, A. (2004). Coralline hydroxyapatite orbital implant (Bio-Eye): Experience with 158 Patients. Ophthal Plast Reconst Surg, 20, 69-74.

33. Shields, C. L., Shields, J. A., Eagle, R. C. \& De Potter, P. (1991). Histopathologic evidence of fibrovascular ingrowth four weeks after placement of the hydroxyapatite orbital implant. Am J Ophthalmol, 111, 363-66.

34. Ferrone, P. J. \& Dutton, J. J. (1992). Rate of vascularization of corraline hydroxyapatite ocular implants. Ophthalmology, 99, 3769.

35. Scolozzi, P. \& Jaques, B. (2004). Treatment of Midfacial Defects Using Prostheses Supported by ITI Dental Implants. Plast Reconstr Surg, 114, 1395-1404.

36. Cheng, A. C., Wee, A. G., Li, J. T. \& Archibald, D. (2002). A new prosthodontic approach for craniofacial implant-retined maxillofacial prostheses. J of Prosthet Dent, 88, 224-228.

37. Hornblass, A., Biesman, B. S. \& Eviatar, J. A. (1995). Current techniques of enucleation: a survey of 5439 intraorbital implants and a review of the literature. Ophthalmol. Plast Reconstr Surg, 11, 77-86.

38. Leonardi, A., Buonaccorsi, S., Pellacchia, V., Moricca, L. M., Indrizzi, E. \& Fini, G. (2008). Maxillofacial prosthetic rehabilitation using extraoral implants. J Craniofac Surg, 19, 398- 405. 